\title{
Differing Impact of Weight Cycling on Ambulatory Blood Pressure versus Conventional Blood Pressure Assessment: A Possible Explanation to Controversy
}

\author{
Zachary Stephen Zeigler*, Trevor Carroll Nordin \\ College of Science, Engineering and Technology, Grand Canyon University, Phoenix, AZ, USA
}

Background: Weight cycling (WC) is a widespread behavior associated with elevated laboratory blood pressure (BP). The impact WC may have on ambulatory BP (ABP) is unknown.

Methods: Impact of self-reported WC history on ABP was assessed via cross-sectional nonexperimental design. Sixty-five women completed the Weight and Lifestyle Inventory (WALI) questionnaire. The WALI has been shown to be a reliable index of WC $(r=0.87, P<0.001)$. Data were analyzed looking at $W C$ both as a continuous and criterion variable, and subjects were dichotomized as either WC or non-WC (NWC).

Results: WC $(n=31)$ were older ( $39.7 \pm 8.9$ vs. $33.1 \pm 11.3$ years), had a higher percent body fat $(47.1 \% \pm 6.2 \%$ vs. $41.4 \% \pm 7.8 \%)$, and were less fit $(21.2 \pm 5.4 \mathrm{vs.} 26.7 \pm 7.6 \mathrm{~mL} / \mathrm{kg} / \mathrm{min})$ than NWC $(\mathrm{n}=34)$. No significant correlation between laboratory systolic $\mathrm{BP}(\mathrm{SBP}, P=0.830)$ or diastolic $\mathrm{BP}(\mathrm{DBP}, P=0.997)$ and WC was observed. A significant correlation between the number of WC and systolic $A B P(r=0.326, P=0.010)$ and trend for diastolic ABP $(r=0.238, P=0.065)$ was found. SBP $(23 \%$ vs. $17 \%, P<0.001)$ and DBP $(13 \%$ vs. $9 \%, P<0.001)$ load was higher for WC compared to NWC women.

Conclusion: WC may deleteriously affect BP outcomes that might only be observed when ABP monitoring is used.

Received May 17, 2019

Reviewed June 18, 2019

Accepted July 23, 2019

${ }^{*}$ Corresponding author

Zachary Stephen Zeigler

https://orcid.org/0000-0002-7690-8221

College of Science, Engineering and Technology, Grand Canyon University, 3300 West Camelback Rd, Phoenix, AZ 85017, USA

Tel: +1-480-200-2416

E-mail: zachary.zeigler@gcu.edu

Key words: Weight, Ambulatory blood pressure, Obesity, Body fat

\section{INTRODUCTION}

National surveys have found that roughly 57\% of women had been on a weight loss diet in the preceding year. ${ }^{1}$ Dishearteningly, upwards of $95 \%$ of those who lose weight cannot sustain weight loss. ${ }^{2}$ Thus, dieters relapse into the predictive pattern of weight loss followed by weight regain sequences termed weight cycling (WC). Granted, there is controversy for the topic of WC. However, data shows that WC is related to redistribution of body fat towards increased abdominal adiposity. ${ }^{3} \mathrm{WC}$ has also been highlighted as a contributor of increased blood pressure (BP). ${ }^{4}$ A 2010 review $^{5}$ analyzed the available data on the impact of WC on BP in overweight/ obese adults. This review found five articles that met inclusion criteria and only one of the five was deemed to be "adequate" quality. Nevertheless, of the five articles, three showed no impact of WC on BP while two showed WC increased BP. The authors determined that there was not enough evidence of acceptable quality to draw definitive conclusions and that additional research is needed for looking at the impact of WC on BP. Surprisingly, none of the involved studies included the superior technique of ambulatory $\mathrm{BP}$ (ABP) monitoring. ${ }^{6}$ To the authors knowledge, there is no data assessing the impact of WC on ABP. Thus, the purpose of this correlational nonexperimental study was to assess $\mathrm{ABP}$ differences between WC and non-WC (NWC) overweight/obese woman. 


\section{METHODS}

The data for current study was collected in correlation with previous published work assessing the impact of WC on arterial stiffness. ${ }^{7}$ Sixty-five healthy, overweight/obese, nonsmoking, weight stable, Caucasian women with a body mass index (BMI) $>25 \mathrm{~kg} / \mathrm{m}^{2}$ and age of 25-60 years were recruited. Subjects did not have diabetes or cardiovascular disease and were not on medication for either. The Grand Canyon University Institutional Review Board approved this study (IRB No. 1087754) and informed consent was obtained prior to enrollment.

Subjects came to the laboratory for a single visit. Anthropometric measures of body weight, height, waist and hip circumferences and body fat (air displacement plethysmography; Bod Pod, Cosmed, Concord, CA, USA) were then measured followed by laboratory BP (Connex ProBP 3400 digital BP device; Welch Allyn, Skaneateles Falls, NY, USA). Next, a peak oxygen uptake $\left(\mathrm{VO}_{2 \text { peak }}\right)$ test was completed. $\mathrm{VO}_{2 \text { peak }}$ was defined as the 10 second highest consecutive two points achieved during the exercise test. Subjects were then given the Weight and Lifestyle Inventory (WALI) questionnaire. ${ }^{8}$ The WALI has been found reliable in reporting number of diets $(\mathrm{r}=0.77)$ and amount of weight lost $(\mathrm{r}=0.87$, both $P<0.001){ }^{9}$ Subjects were classified as weight cyclers (WC group) if they reported a weight loss of $\geq 4.5 \mathrm{~kg}$ followed by weight regain of at least three times. ${ }^{10,11}$ An ABP monitor was given to the subjects (Oscar 2 ABP System; SunTech Medical, Morrisville, NC, USA). ${ }^{12}$ The Oscar 2 was programmed to take readings every 15 minutes throughout the day (09:00 AM-22:00 PM).

\section{Statistical analysis}

Statistical analyses were performed using IBM SPSS version 24.0 (IBM Corp., Armonk, NY, USA). Statistical analysis included ABP data collected from 09:00 AM to 22:00 PM of the same day. Mean day time $\mathrm{ABP}$ between groups were compared using independent t-test. Confounding variables of age, body fat, and $\mathrm{VO}_{2 \text { peak }}$ were then included as covariates via general linear models. Chi-square tests were used to compare frequency differences in BP load (percentage of readings above 140/90 mmHg). Bivariate Pearson correlations were used to assess linear relationships between number of WC's, as a continuous variable, and systolic and diastolic laboratory BP and mean ABP. Hierarchical regression was used to assess if WC significantly added to the model above what age, body fat, waist-tohip ratio and $\mathrm{VO}_{2 \text { peak }}$ contribute to predicting $\mathrm{BP}$ outcomes.

\section{RESULTS}

Sixty-five overweight/obese female subjects completed the study. WC women were older, carried more body fat overall and in the abdominal region, and were not as fit as NWC women (Table 1). Table 1 illustrates that there was no statistical difference in resting (laboratory) systolic BP (SBP) and diastolic BP (DBP) between groups. However, there were statistical differences in mean systolic $\mathrm{ABP}$ and diastolic $\mathrm{ABP}$. Because mean group differences were found for age, body fat, waist-to-hip ratio, and $\mathrm{VO}_{2 \text { peak, }}$ these variables were then adjusted for as covariates. Due to collinearity of body fat, BMI, and waist-to-hip ratio, these variables were included alternately. After adjusting for age, there were still differences between groups for systolic ABP $(P=0.040)$ and borderline significant difference for diastolic $\mathrm{ABP}(P=0.056)$. There was a trend for statistical significance on systolic ABP after adding body fat as a covariate $(P=0.062)$ while significance was completely lost for diastolic ABP $(P=0.123)$. There were still significant systolic and diastolic ABP differences between groups after adjusting for waist-tohip-ratio ( $P=0.014, P=0.017$, respectively).

Because baseline differences in BMI were seen between WC and NWC groups, and since BMI undoubtedly affects $B P$ values, the data was then split into obese $\left(B M I \geq 30 \mathrm{~kg} / \mathrm{m}^{2}, \mathrm{n}=37\right)$ and non-

Table 1. Demographics

\begin{tabular}{lccc}
\hline Variable & WC group $(\mathrm{n}=31)$ & NWC group $(\mathrm{n}=34)$ & $P$ \\
\hline No. of cycles & $5.3 \pm 1.8$ & $1.6 \pm 1.1$ & $<0.001^{*}$ \\
BMl $\left(\mathrm{kg} / \mathrm{m}^{2}\right)$ & $36.6 \pm 6.5$ & $29.7 \pm 5.3$ & $<0.001^{*}$ \\
Body fat $(\%)$ & $47.1 \pm 6.2$ & $41.4 \pm 7.8$ & $0.002^{*}$ \\
Waist to hip ratio & $0.83 \pm 0.12$ & $0.71 \pm 0.23$ & $0.015^{*}$ \\
Age $(\mathrm{yr})$ & $39.7 \pm 8.9$ & $33.1 \pm 11.3$ & $0.012^{*}$ \\
VO $_{\text {2peak }}(\mathrm{mL} / \mathrm{kg} / \mathrm{min})$ & $21.2 \pm 5.4$ & $26.7 \pm 7.6$ & $0.002^{*}$ \\
Resting SBP $(\mathrm{mmHg})$ & $126.5 \pm 14.1$ & $123.5 \pm 11.3$ & 0.499 \\
Resting DBP $(\mathrm{mmHg})$ & $77.7 \pm 10.3$ & $76.2 \pm 7.1$ & 0.525 \\
Ambulatory SBP $(\mathrm{mmHg})$ & $130.1 \pm 13.6$ & $122.0 \pm 8.2$ & $0.006^{*}$ \\
Ambulatory DBP $(\mathrm{mmHg})$ & $76.2 \pm 8.9$ & $70.0 \pm 9.0$ & $0.011^{*}$ \\
\hline
\end{tabular}

Values are presented as mean \pm standard deviation.

*Unadjusted $P$-values.

$\mathrm{WC}$, weight cycling; $\mathrm{NWC}$, non-WC; $\mathrm{BMI}$, body mass index; $\mathrm{VO}_{2 \text { peak, }}$ peak oxygen uptake; SBP, systolic blood pressure; DBP, diastolic blood pressure. 
obese (BMI $\left.<30 \mathrm{~kg} / \mathrm{m}^{2}, \mathrm{n}=28\right)$ subjects. Within the obese subjects, there was no difference in laboratory SBP between WC $(n=23)$ and NWC ( $\mathrm{n}=14)$ groups $(129.9 \pm 13.9$ vs. $128.4 \pm 12.4 \mathrm{mmHg}$, respectively, $P=0.740)$. However, there was a significant group difference in systolic ABP (132.5 \pm 12.5 vs. $125.2 \pm 8.7 \mathrm{mmHg}, P=$ 0.048 ) such that WC had higher values. However, after adding baseline $\mathrm{BMI}$ and age into the model as covariates, statistical significance was lost $(P=0.468)$. There were no group differences for laboratory $(P=0.995)$ or ambulatory DBP $(P=0.101)$. When analyzing the non-obese group in isolation, there were no group differences for laboratory $\operatorname{SBP}(P=0.378), \mathrm{DBP}(P=0.484)$, ambulatory $\operatorname{SBP}(P=0.374)$ or ambulatory DBP $(P=0.357)$.

No significant correlation between laboratory SBP and the number of WC's was observed $(P=0.830)$. A significant correlation between the number of WC's and mean systolic ABP exists $(r=0.326$, $P=0.010)$. Number of WC did not correlate with laboratory DBP $(P=0.997)$ but there was a trend for number of WC to correlate with diastolic $\mathrm{ABP}(\mathrm{r}=0.238, P=0.065)$. A hieratical regression analysis was conducted with age, BMI, fitness, and waist circumference entered into the first model as predictor variables and WC (as a continuous variable) entered into the second model as a predictor variable with $\mathrm{ABP}$ as the criterion variable. The first model significantly explained $39.0 \%$ of the variance on systolic $\mathrm{ABP}(\mathrm{r}=$ $0.624, P<0.001)$. The addition of WC showed an $r$-square change that added $4 \%$ of the variance being explained by WC $(P=0.068)$. When diastolic $\mathrm{ABP}$ was used as the criterion variable, the first model significantly explained $28.6 \%(\mathrm{r}=0.534, P=0.001)$ but the addition of WC did not enhance the prediction model $(P=0.865)$.

Fig. 1A shows no statistical difference between WC and NWC on the percentage of SBP readings of $<120$ or $120-139 \mathrm{mmHg}$ $(P>0.05)$. However, there was a higher percentage of SBP readings above $140 \mathrm{mmHg}$ for WC compared to NWC (23\% vs. $17 \%$, $P<0.001)$. Fig. 1B shows a statistically greater percentage of normal DBP readings ( $<80 \mathrm{mmHg}$ ) for NWC compared to WC ( $75 \%$ vs. $69 \%$, respectively, $P<0.001$ ). There were no differences on the percentage of DBP readings $80-89 \mathrm{mmHg}$ but there was a statistically higher percentage of DBP readings above $90 \mathrm{mmHg}$ for WC compared to NWC ( $13 \%$ vs. $9 \%, P<0.001)$.
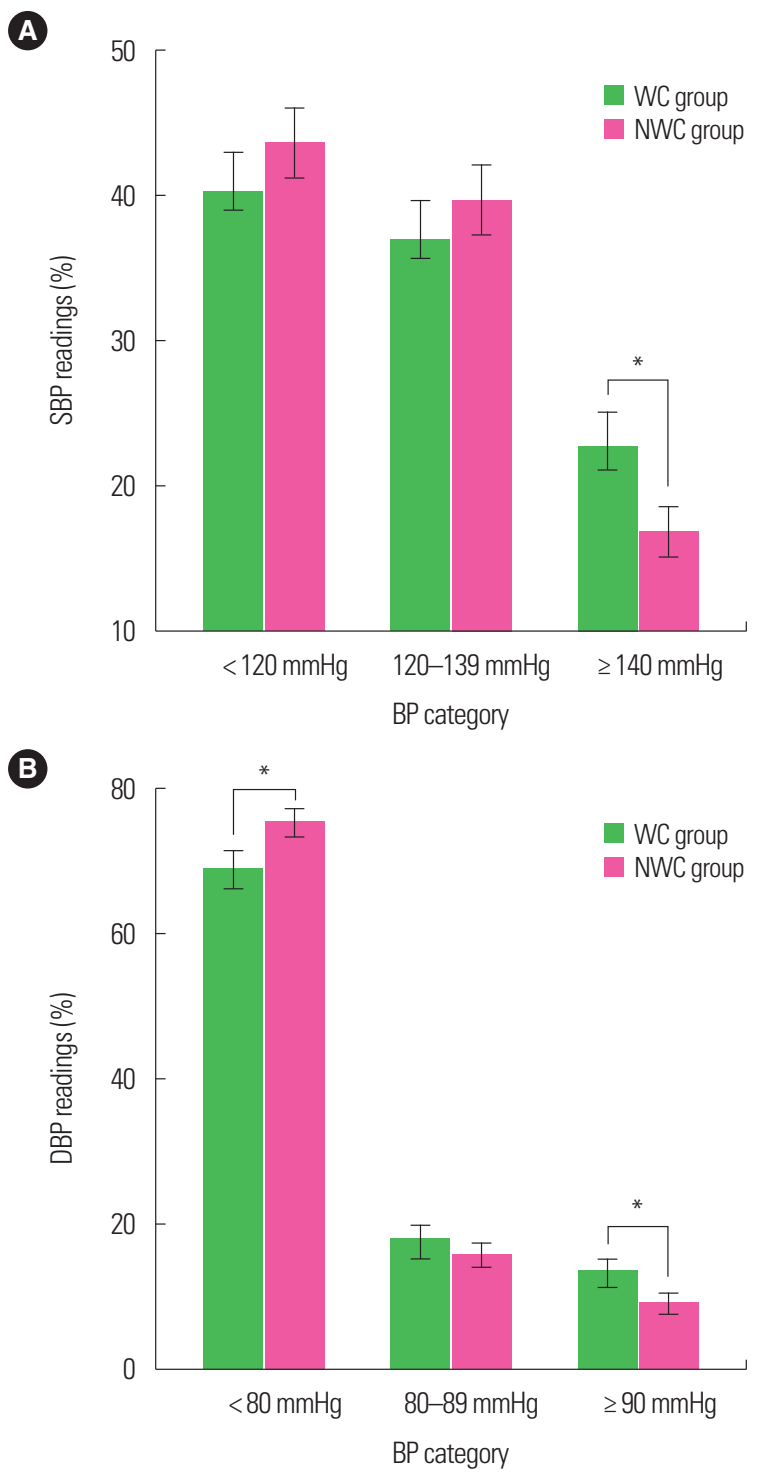

Figure 1. Percentage of systolic (SBP) and diastolic blood pressure (DBP) according to weight cycling (WC). Difference in percentage of SBP (A) and DBP (B) category readings between $W C$ and non-WC (NWC) groups (over 13 hours, 09:00 AM-22:00 PM). Error bar represents $95 \%$ confidence interval. ${ }^{*} P<0.05$ from chisquare test to compare WC and NWC groups.

\section{DISCUSSION}

To the authors knowledge, this is the first study to assess the possible impact of WC on $\mathrm{ABP}$. The major finding of this investigation was that WC did not affect laboratory BP but may have an impact on daytime $\mathrm{ABP}$, including $\mathrm{BP}$ load. This is significant because past literature assessing the impact of WC on $\mathrm{BP}$ has been inconclusive possibly due to the method of $\mathrm{BP}$ measurement.

Zeigler et al. 7 found higher levels of WC were associated with in- 
creased laboratory BP values and arterial stiffness, mainly through the mediating impact of increased visceral fat. The current study supports the role of WC on abdominal obesity in that the WC group had a significantly higher waist-to-hip ratio compared to the NWC group. In addition to abdominal obesity, BMI has also been shown to be associated with increased $A B P$ values ${ }^{13}$ and $W C$ has been shown to be associated with increased BMI. ${ }^{14}$ When subjects were dichotomized either as WC or NWC and was analyzed by BMI, ABP values were still higher in the WC groups. However, because BMI was still higher in the WC group (39.2 \pm 5.2 vs. $35.1 \pm$ $\left.3.6 \mathrm{~kg} / \mathrm{m}^{2}, P=0.014\right)$, baseline BMI was entered as a covariate and the analysis re-ran. Statistical significance was then completely lost. Suggesting that BMI is a possible mediator between WC behavior and $\mathrm{BP}$ values. Attention needs to be called to the fact that although significance was lost after adjusting for baseline BP values, differences were seen between the two BP assessment techniques in every analysis of the study. This highlights the need for the use of the superior $\mathrm{ABP}$ technique when gaging the impact of weight fluctuations on BP outcomes. Prior research in this area that has focused on a one-time BP assessment assuming it represents the impact of BP on cardiovascular health may have missed the deleterious effects of WC.

\section{CONFLICTS OF INTEREST}

The authors declare no conflict of interest.

\section{ACKNOWLEDGMENTS}

We thank the undergraduate research assistants working at the Health Information and Programing Clinic at Grand Canyon University.

\section{AUTHOR CONTRIBUTIONS}

Study concept and design: ZSZ; acquisition of data: ZSZ; analysis and interpretation of data: all authors; drafting of the manuscript: all authors; critical revision of the manuscript: all authors; statistical analysis: ZSZ; administrative, technical, or material support: ZSZ; and study supervision: all authors.

\section{REFERENCES}

1. Yaemsiri S, Slining MM, Agarwal SK. Perceived weight status, overweight diagnosis, and weight control among US adults: the NHANES 2003-2008 Study. Int J Obes (Lond) 2011;35: 1063-70.

2. Stunkard A, McLaren-Hume M. The results of treatment for obesity: a review of the literature and report of a series. AMA Arch Intern Med 1959;103:79-85.

3. Wallner SJ, Luschnigg N, Schnedl WJ, Lahousen T, Sudi K, Crailsheim K, et al. Body fat distribution of overweight females with a history of weight cycling. Int J Obes Relat Metab Disord 2004;28:1143-8.

4. Zhang H, Tamakoshi K, Yatsuya H, Murata C, Wada K, Otsu$\mathrm{ka} \mathrm{R}$, et al. Long-term body weight fluctuation is associated with metabolic syndrome independent of current body mass index among Japanese men. Circ J 2005;69:13-8.

5. Adolfsson C, Classon ID. Effect of weight cycling on blood pressure in overweight and obese adults: a systematic review. Gothenburg: Gothenburg University; 2010.

6. Pickering TG, Shimbo D, Haas D. Ambulatory blood-pressure monitoring. N Engl J Med 2006;354:2368-74.

7. Zeigler ZS, Birchfield N, Moreno K, James D, Swan P. Fatness and fluctuating body weight: effect on central vasculature. Biores Open Access 2018;7:90-100.

8. Wadden TA, Foster GD. Weight and Lifestyle Inventory (WALI). Obesity (Silver Spring) 2006;14 Suppl 2:99S-118S.

9. Wadden TA, Bartlett S, Letizia KA, Foster GD, Stunkard AJ, Conill A. Relationship of dieting history to resting metabolic rate, body composition, eating behavior, and subsequent weight loss. Am J Clin Nutr 1992;56(1 Suppl):203S-208S.

10. Field AE, Manson JE, Laird N, Williamson DF, Willett WC, Colditz GA. Weight cycling and the risk of developing type 2 diabetes among adult women in the United States. Obes Res 2004;12:267-74.

11.Lahti-Koski M, Männistö S, Pietinen P, Vartiainen E. Prevalence of weight cycling and its relation to health indicators in Finland. Obes Res 2005;13:333-41.

12. Goodwin J, Bilous M, Winship S, Finn P, Jones SC. Validation of the Oscar 2 oscillometric 24-h ambulatory blood pressure 
monitor according to the British Hypertension Society protocol. Blood Press Monit 2007;12:113-7.

13. Kotsis V, Stabouli S, Bouldin M, Low A, Toumanidis S, Zakopoulos N. Impact of obesity on 24-hour ambulatory blood pressure and hypertension. Hypertension 2005;45:602-7.
14. Kroke A, Liese AD, Schulz M, Bergmann MM, Klipstein-Grobusch K, Hoffmann K, et al. Recent weight changes and weight cycling as predictors of subsequent two year weight change in a middle-aged cohort. Int J Obes Relat Metab Disord 2002; 26:403-9. 